\title{
Factors associated with the development of self-harm amongst a socio-economically deprived cohort of adolescents in Santiago, Chile
}

\author{
Melissa Spears • Alan A. Montgomery • \\ David Gunnell · Ricardo Araya
}

Received: 5 April 2013/Accepted: 17 September 2013/Published online: 6 October 2013

(C) The Author(s) 2013. This article is published with open access at Springerlink.com

\begin{abstract}
Purpose Studies carried out in the West indicate that the incidence of self-harm (SH) is particularly high amongst adolescents, but few studies have investigated its incidence and aetiology in low-income countries. The purpose of this study was to investigate risk factors associated with new onset episodes of $\mathrm{SH}$, amongst Chilean adolescents from low socio-economic backgrounds.

Methods Prospective cohort study nested within a cluster randomised controlled trial. A 6-month follow-up for 2,042 adolescents, median age 14 years, from socio-economically deprived areas of Santiago, Chile.

Results The lifetime prevalence of $\mathrm{SH}$ was $23 \%$. The incidence rate of SH at 6 months was $14 \%$ amongst those reporting no $\mathrm{SH}$ at baseline. In multivariable analyses, risk factors for incident $\mathrm{SH}$ include depressive symptoms, suicidal thoughts, poor problem-solving skills and cannabis misuse.

Conclusions The prevalence and incidence of SH in this socio-economically deprived sample differed highly
\end{abstract}

Electronic supplementary material The online version of this article (doi:10.1007/s00127-013-0767-y) contains supplementary material, which is available to authorized users.

M. Spears · D. Gunnell · R. Araya ( $\square)$

Academic Unit of Psychiatry, School of Social

and Community Medicine, University of Bristol,

Oakfield Grove, Bristol BS8 2BN, UK

e-mail: mhxra@bristol.ac.uk

\section{A. A. Montgomery}

Medical Statistics and Clinical Trials, Nottingham Clinical Trials Unit, Nottingham Health Science Partners, C Floor, South Block, Queen's Medical Centre, Nottingham NG7 2UH, UK

e-mail: alan.montgomery@nottingham.ac.uk

URL: http://www.nottingham.ac.uk/nctu/home according to gender. Poor problem-solving skills, suicidal thoughts, and cannabis misuse were associated with onset of SH.

Keywords Self-harm · Adolescents · Depression · Prospective $\cdot$ Deprived

\section{Introduction}

Suicide is a leading cause of death amongst adolescents in both low- and high-income countries [1]. Previous non-fatal $\mathrm{SH}$ is one of the strongest risk factors for suicide [2], and risk factors for $\mathrm{SH}$ are similar to those for suicide [3].

The incidence of SH is high amongst adolescents, particularly females, although these differences are partly associated with the earlier age of puberty/earlier maturational development in girls [4]. Previous research amongst adolescents, although almost all in developed countries, shows lifetime prevalence ranging from 2 to $23 \%$ and the main reasons given for $\mathrm{SH}$ in adolescents are a desire to get relief from a terrible state of mind, a wish to die or to punish oneself [5-7].

Risk factors for SH include: low self-esteem, depression, anxiety, coming from a single parent family, poor family relationships and other relationship problems, impulsivity, being bullied, physical and sexual abuse, drug misuse, smoking, alcohol misuse, and female sex [8,9]. Awareness of friends or family who self-harmed, along with permissive group norms towards $\mathrm{SH}$, is also thought to be influential [10]. Risk factors amongst adolescents include symptoms of depression and anxiety, antisocial behaviour, high-risk alcohol use, cannabis use, and cigarette smoking [11, 12]. 
Gender differences in $\mathrm{SH}$ are also well recognised [2, 8, 13]. Females are more likely to engage in SH than males, with one study finding girls to be three times more likely to SH than boys (13.9 vs. $4.3 \%$ ) and similar findings within the ALSPAC cohort data $(25.6 \%$ in girls vs. $9.1 \%$ in boys) [6, 14]. The prevalence of thoughts about $\mathrm{SH}$ has also been found to be higher for females, $21.5 \%$, as compared to $9.9 \%$ for males [5].

Most previous investigations of $\mathrm{SH}$ risk factors have been carried out in developed countries and have tended to be based on cross-sectional surveys. To our knowledge there have been no previous studies of $\mathrm{SH}$ incidence in South America. Cross-sectional population studies in developing countries found the lifetime prevalence of suicide ideation and attempts to be as high as that in the developed world $[15,16]$. Research in developing countries has investigated risk factors for completed suicide rather than for SH. These have found that the main risk factors are similar to those reported in developed countries, and include previous $\mathrm{SH}$, substance misuse, low socio-economic position, and psychiatric disorder [17]. It is thought that those adolescents who find it difficult to cope with their difficulties or feel disconnected with their immediate environment are more likely to resort to $\mathrm{SH}[18,19]$ but there is not yet any evidence from prospective studies for these associations.

The aim of this study was to investigate risk factors associated with incident $\mathrm{SH}$ and to consider how changes over time in potential risk factors are associated with incident SH among adolescents in Santiago, Chile.

\section{Sample and methods}

\section{Participants and procedures}

The data presented here are from a cohort study nested within a cluster randomised controlled trial of a schoolbased intervention aimed at reducing depressive symptoms among Chilean secondary school students [20]. Consent from carriers and assent from students were both required for participation. All but two students provided data for this study. Ethical approval was obtained from the local Committee in Chile (Hospital Clinico Universidad de Chile).

Participants were aged 12-18 years, with virtually all between 13 and 16 years old. All were in year 10 of 22 state-funded mixed-sex secondary schools in socio-economically deprived areas of Santiago, Chile. Beyond the selection of schools there was no further selection of specific individuals; all students within year 10 were eligible to take part in the trial and thus all were included unless consent was not given or individuals opted out.
Measures

Self-reported questionnaires were completed at school, during lesson time, in sessions led by the research team. They were completed at baseline and 6 months later. The questionnaires included measures of depression, anxiety, problem solving, school connectedness, risk behaviours (cigarette smoking, drinking alcohol, misusing cannabis) and suicidal thoughts, with self-reported $\mathrm{SH}$ as the main outcome.

Self-harm, suicidal thoughts and suicidal intent

SH was assessed by asking "Have you ever intended to take your own life or have you self-harmed for example by overdosing or cutting your arms?" (Yes/No). Suicidal thoughts were assessed using the following question "Have you thought about ending your life in the last 14 days?" (Yes/Yes but not in the last 14 days/No). SH method was classified using the question "The last time you selfharmed on purpose, which best describes what you did?" (Ingested pills or poison/cut myself/burnt myself for example with cigarettes/other). This question was used to define likelihood of suicidal intent in the sub-sample reporting method, with ingesting pills or poison indicative of SH with suicidal intent and other methods more indicative of $\mathrm{SH}$ without suicidal intent, and thus look at assessing gender differences in $\mathrm{SH}$ with and without suicidal intent. Those ticking other were classified as being without suicidal intent.

Mood, school connectedness and rational problemsolving ability

Depressive symptoms were assessed by the 21-item Beck Depression Inventory (BDI-II) [21], a self-completed questionnaire generating a total score between 0 and 63 . This has previously been validated in Spanish and used among adolescents in Chile [22]. Scores were dichotomised with high risk defined as a BDI-II score $\geq 20$ for females and $\geq 14$ for males, according to our own validation study.

Anxiety was assessed by the continuous 5-item general anxiety subscale (GAD) of the Revised Children's Anxiety and Depression Scale (RCADS) [23]. This was dichotomised around the median, with a GAD score $\geq 7$ points defined as high anxiety.

School connectedness was assessed by the 8-item Psychological Sense of School Membership (PSSM) [24]. This scale assesses the degree to which students feel valued, respected and included within school. It was dichotomised around the sample median, with a PSSM score $\geq 19$ defined as good school connectedness.

Problem-solving ability was assessed using the short form of the Social Problem-Solving Inventory Revised, 
Rational Problem-Solving subscale [25]. This is a 20-item scale, with each item rated on a 5-point scale ranging from "not at all true of me" (0) to "extremely true of me" (4). This total score was dichotomised around the median, with a score $\geq 45$ defined as good problem-solving abilities. Examples of statements to be rated by participants include "When I make decisions, I don't only consider the immediate consequences of each possible alternative, but also long-term consequences", "When I'm trying to decide which is the best solution to a problem I usually consider the effect each alternative may have on my personal feelings", "When I have a problem to solve, one of the things I do is to examine what kind of circumstances in my environment have contributed to the problem".

Tobacco, alcohol and drug consumption over last 30 days

Students were asked about their drinking of alcohol (dichotomised into 0 "Never" versus 1 "At least once"), use of cannabis (dichotomised into 0 "Never" versus 1 "At least once") and smoking (dichotomised into 0 "Never" versus 1 "At least once"). The same questions were asked at both baseline and the follow-up time points.

\section{Statistical analyses}

Analyses addressed the following four areas:

1. Lifetime prevalence of $\mathrm{SH}$ and suicidal thoughts based on information provided at baseline.

2. Risk factors associated with incident $\mathrm{SH}$ at 6 months in the sub-sample of individuals reporting no previous $\mathrm{SH}$ at baseline, using both univariable and multivariable adjusted logistic regression models.

3. Gender differences in incident $\mathrm{SH}$ according to whether SH was perceived to be with or without suicidal intent, as defined by reported SH method.

4. The association of changes in risk factor status, between baseline and 6-month follow-up, with onset of SH (new case) by 6-month follow-up estimated as odds of incident $\mathrm{SH}$.

Our main analyses are based on data provided by participants who completed the SH item at both baseline and 6-month follow-up. We also compared baseline characteristics of those with and without reported $\mathrm{SH}$ status at either assessment point. Those reporting $\mathrm{SH}$ at baseline are not included in analyses of incidence, as they cannot be considered new cases of $\mathrm{SH}$.

Baseline characteristics were described using means and standard deviations (SD) or median and inter-quartile range (IQR) and numbers and percentages, for continuous and categorical variables, respectively. These are presented for males and females separately and also overall for the whole sample.

Incident $\mathrm{SH}$ was defined as new reporting of $\mathrm{SH}$, classified as answering yes to the question "Have you ever intended to take your own life or have you selfharmed for example by overdosing or cutting your arms?" at 6-month follow-up amongst those reporting no previous $\mathrm{SH}$ at baseline assessment. We investigated crude and adjusted associations between baseline measures and incident $\mathrm{SH}$ using logistic regression models. Analyses were conducted for males and females combined, and multivariable logistic regression models included terms for age, gender and trial arm as confounders. Gender was included as an interaction within the multivariable models, to test for statistical evidence of a difference between males and females for each of the risk factors. Where evidence of a gender interaction was found $(p<0.1)$, the separate odds ratios for males and females are given in the text.

Since the question used to determine an individual's SH status did not distinguish between $\mathrm{SH}$ with or without suicidal intent, separate analyses were performed to explore whether there was a gender difference in reporting incident SH as non-suicidal or with suicidal intent. Suicidal intent was considered when individuals reported ingesting pills or poison. In contrast, non-suicidal SH was classified when individuals reported cutting or burning themselves or 'other'. These classifications were used as self-poisoning/ overdosing is thought to be more strongly associated with suicidal intent [14].

Multi-level logistic regression models with terms for school and class were investigated to take account of clustering within the data. Neither made any material difference to the estimates and their standard errors so the data presented here are those from simple logistic regression models.

Sensitivity analyses were conducted to assess the potential effect of missing data, using multiple imputations based on variables predictive of missing SH status. Adjusted univariable odds ratios from imputed data are displayed alongside odds ratios for the cross-sectional analysis only. Since these results showed little difference from the observed data, imputations were not calculated for the analysis considering changes from baseline to 6-month followup. All analyses were conducted using Stata version 12.

\section{Results}

Sample characteristics

A total of 2,508 young people [99.9\% of the eligible sample $(N=2,510)]$ consented to take part in the study of whom $81 \%(n=2042)$ completed questions relating to 
$\mathrm{SH}$ at baseline and again at 6-month follow-up. Individuals were aged 12-18 years (median 14 years, IQR $14-15$ years).

Previous SH and suicidal thoughts

Twenty-three percent $(n=460 / 2,042)$ of the participants reported previous $\mathrm{SH}$ at baseline. This prevalence at baseline was higher amongst girls (34\%) than boys (13\%), (OR 3.57, $95 \%$ CI 2.85-4.48). Similarly, prevalence of suicidal thoughts and reports that life was not worth living, in the 14 days prior to the baseline assessment, were both higher for girls (28 and $23 \%$, respectively) than boys (11 and $11 \%$ ).

Within our sample $33 \%$ report SH on at least one follow-up $(n=(460+220) / 2,042)$, with this being particularly high for girls at $47 \%(n=(316+124) / 933)$. In addition, of these individuals reporting SH $93 \%(n=430 /$ $460)$ at baseline and $96 \%(n=495 / 514)$ at 6 months report a method as well.

A comparison of participants with complete and incomplete SH data at baseline and 6-month follow-up indicated those with incomplete data were more likely to be male, smoking regularly (at least once a week), drinking alcohol, and misusing cannabis (at least once in the previous 30 days) (Table $\mathrm{S} 1$ ).

\section{Baseline variables associated with incident $\mathrm{SH}$}

Characteristics of the 1,582 (77\%) participants reporting no $\mathrm{SH}$ at baseline are given in Table 1 . Nearly two-thirds were male, $9.5 \%$ had a previous GP diagnosis of mental illness, $8.2 \%$ reported previous suicidal thoughts and had high levels of cigarette smoking and alcohol consumption. At 6-month follow-up, $14 \%(n=220 / 1,582)$ of participants with no reported $\mathrm{SH}$ at baseline reported incident $\mathrm{SH}$. Incident SH was more likely among girls (20\%) than boys (10\%) (crude OR 2.27, $95 \%$ CI 1.70-3.04).

Associations between those variables measured at baseline and incident $\mathrm{SH}$ are shown in Table 2. After adjustment for all other measured variables there were positive associations with incident SH for high BDI-II scores, suicidal thoughts, poor problem solving and smoking. $p$ values for interactions between gender and each of the measured risk factors ranged from 0.142 to 0.943 , indicating weak evidence that any associations between risk factors and $\mathrm{SH}$ were different for girls and boys.

Incident SH type and gender differences

Of those individuals reporting incident $\mathrm{SH}$ at 6-month follow-up, $96 \%(n=211 / 220)$ also gave information on the type of SH. Of these, $66 \%(n=140)$ described
Table 1 Baseline sample characteristics (of those students reporting no $\mathrm{SH}$ at baseline) overall and by gender

\begin{tabular}{|c|c|c|c|}
\hline Variable & $\begin{array}{l}\text { Boys } \\
N=965 \\
(61 \%)\end{array}$ & $\begin{array}{l}\text { Girls } \\
N=617 \\
(39 \%)\end{array}$ & $\begin{array}{l}\text { Overall } \\
N=1,582\end{array}$ \\
\hline Smoking (last 30 days) & $261(27.1)$ & $185(30.0)$ & $446(28.2)$ \\
\hline Alcohol (last 30 days) & $246(25.5)$ & $132(21.4)$ & 378 (23.9) \\
\hline Cannabis (last 30 days) & $69(7.2)$ & $46(7.5)$ & $115(7.3)$ \\
\hline $\begin{array}{r}\text { GP mental illness } \\
\text { diagnosis (ever) }\end{array}$ & $81(8.4)$ & $69(11.2)$ & $150(9.5)$ \\
\hline $\begin{array}{l}\text { Life's not worth living } \\
\text { (last } 14 \text { days) }\end{array}$ & $79(8.2)$ & $75(12.2)$ & $154(9.8)$ \\
\hline $\begin{array}{l}\text { Suicidal thoughts (last } \\
14 \text { days) }\end{array}$ & $61(6.3)$ & $69(11.2)$ & $130(8.2)$ \\
\hline $\begin{array}{l}\text { Plans of suicide (last } \\
14 \text { days) }\end{array}$ & $10(1.0)$ & $15(2.4)$ & $25(1.6)$ \\
\hline Age, mean (SD) & $14.4(0.8)$ & $14.3(0.8)$ & $14.4(0.8)$ \\
\hline $\begin{array}{l}\text { Beck Depression } \\
\text { Inventory, median } \\
\text { (IQR) }\end{array}$ & $8(4,13)$ & $11(6,18)$ & $9(5,15)$ \\
\hline $\begin{array}{l}\text { Generalised anxiety } \\
\text { disorder, mean (SD) }\end{array}$ & $6.9(3.5)$ & $7.6(3.6)$ & $7.2(3.6)$ \\
\hline $\begin{array}{l}\text { School connectedness, } \\
\text { mean (SD) }\end{array}$ & $19(4.0)$ & $19.4(3.6)$ & $19.2(3.8)$ \\
\hline $\begin{array}{l}\text { Rational problem solving, } \\
\text { mean (SD) }\end{array}$ & $45.6(13.2)$ & $46.2(11.6)$ & $45.8(12.6)$ \\
\hline
\end{tabular}

Figures are number (percentage) of students unless otherwise stated

incident $\mathrm{SH}$ as either cutting or burning, $17 \%(n=35)$ reported ingestion of poison or pills (that is with a greater likelihood of having suicidal intent), and the remaining $17 \%$ described incident $\mathrm{SH}$ as 'other' unspecified type.

There was evidence of a difference between boys and girls in reported method of incident $\mathrm{SH}$, amongst those reporting incident $\mathrm{SH}$, with girls being more likely than boys to report ingesting pills or poison (girls $23 \%$, boys $8 \%$, OR 3.92, $95 \%$ CI 1.49-10.28).

Changes in risk factors and incident $\mathrm{SH}$ at 6-month follow-up

Univariable odds ratios indicated that changes between baseline and 6 months in BDI-II scores, anxiety scores, rational problem-solving ability, suicidal thoughts, alcohol consumption, cannabis misuse, and smoking were all associated with incident SH (Table 3). After adjusting for all other measured variables most associations were considerably attenuated, but there remained some evidence that high BDI-II scores, poor problem-solving skills and suicidal thoughts were associated with incident $\mathrm{SH}$ amongst both boys and girls. We investigated whether associations with any of the eight risk factors investigated differed in boys and girls. We found limited evidence of gender differences for all but one factor: persistent 
Table 2 Mood, suicidal thoughts and other risk factors for incident $\mathrm{SH}$

\begin{tabular}{|c|c|c|c|c|c|}
\hline Baseline variable & Level & $\begin{array}{l}\mathrm{SH} \text { at } 6 \text { months/no } \\
\mathrm{SH} \text { at baseline }\end{array}$ & $\begin{array}{l}\text { Adjusted OR }{ }^{\mathrm{a}} \\
(95 \% \mathrm{CI})\end{array}$ & $\begin{array}{l}\text { Multiple adjusted } \\
\mathrm{OR}^{\mathrm{b}}(95 \% \mathrm{CI})\end{array}$ & $\begin{array}{l}\text { Multiple adjusted OR } \\
(95 \% \text { CI }) \text { from MI }\end{array}$ \\
\hline \multirow[t]{2}{*}{$\mathrm{BDI}^{\mathrm{c}}$ category } & Low & $129 / 1233$ & 1.0 & 1.0 & 1.0 \\
\hline & $\operatorname{High}^{\mathrm{d}}$ & $91 / 348$ & $3.27(2.39,4.47)$ & $2.45(1.73,3.47)$ & $2.30(1.65,3.20)$ \\
\hline \multirow[t]{2}{*}{ Anxiety } & Low & $81 / 736$ & 1.0 & 1.0 & 1.0 \\
\hline & $\operatorname{High}^{\mathrm{e}}$ & $139 / 846$ & $1.45(1.08,1.96)$ & $1.18(0.85,1.63)$ & $1.20(0.87,1.64)$ \\
\hline \multirow[t]{2}{*}{ School connectedness } & Good $^{\mathrm{f}}$ & $130 / 952$ & 1.0 & 1.0 & 1.0 \\
\hline & Poor & $90 / 630$ & $1.06(0.79,1.43)$ & $0.81(0.59,1.12)$ & $0.82(0.60,1.13)$ \\
\hline \multirow[t]{2}{*}{ Rational problem solving } & Good $^{\mathrm{g}}$ & $101 / 863$ & 1.0 & 1.0 & 1.0 \\
\hline & Poor & $119 / 719$ & $1.53(1.14,2.05)$ & $1.50(1.09,2.05)$ & $1.14(1.09,1.97)$ \\
\hline \multirow[t]{2}{*}{ Suicidal thoughts } & No & $171 / 1452$ & 1.0 & 1.0 & 1.0 \\
\hline & Yes & $49 / 130$ & $4.14(2.78,6.17)$ & $2.68(1.73,4.14)$ & $2.57(1.71,3.86)$ \\
\hline \multirow[t]{2}{*}{ Alcohol } & Never & $159 / 1202$ & 1.0 & 1.0 & 1.0 \\
\hline & Ever & $61 / 378$ & $1.32(0.95,1.83)$ & $0.86(0.58,1.26)$ & $0.89(0.60,1.34)$ \\
\hline \multirow[t]{2}{*}{ Cannabis } & Never & $192 / 1463$ & 1.0 & 1.0 & 1.0 \\
\hline & Ever & $28 / 115$ & $2.09(1.30,3.38)$ & $1.46(0.85,2.51)$ & $1.43(0.83,2.49)$ \\
\hline \multirow[t]{2}{*}{ Smoking } & Never & $133 / 1135$ & 1.0 & 1.0 & 1.0 \\
\hline & Ever & $87 / 446$ & $1.83(1.34,2.49)$ & $1.59(1.11,2.28)$ & $1.53(1.08,2.19)$ \\
\hline
\end{tabular}

a ORs adjusted for age, gender and trial arm

b ORs adjusted for age, gender, trial arm and all other variables

c Beck Depression Inventory

d $\geq 20$ in females, $\geq 14$ in males

e $\geq 7$ in females and males

${ }^{\mathrm{f}} \geq 19$ in females and males

$\mathrm{g} \geq 45$ in females and males

cannabis misuse was associated with increased odds of incident $\mathrm{SH}$ amongst girls only ( $p$ value for interaction 0.054). Looking at the ORs for girls and boys separately those girls who persistently misused cannabis were seen to be at slightly increased risk of SH (OR $1.1495 \% \mathrm{CI}$ 0.36-3.60 for boys and OR 4.08 95\% CI 1.31-12.74 for girls). It is important, however, to note that several tests of interaction were carried out and thus, there was an increased likelihood of finding an interaction by chance.

\section{Discussion}

\section{Principal findings}

As far as we are aware this is the first longitudinal prospective study of SH in a sample of South American adolescents. Amongst the most salient findings of this study we should highlight the high prevalence and incidence of $\mathrm{SH}$ in this socio-economically deprived population, especially amongst girls. A sizeable proportion of students reported not just thinking about suicide, but also actively attempting it or self-harming. This study provides further confirmation that smoking, depressive symptoms, and suicidal thoughts are commonly associated with incident SH. Increased risk was also associated with cannabis use, but only amongst girls, and poor problem solving amongst both boys and girls. These findings underscore the magnitude of this problem among youngsters in this setting and possibly other similar low socio-economic areas within non-western countries, a relatively neglected research topic.

Both prevalent and incident SH were much higher than observed in other previous population-based studies of $\mathrm{SH}$ in high-income countries, where a prevalence of around $10 \%$ has been reported [12, 26, 27]. Although these higher rates may be partly explained both because the sample comprised adolescents from low socio-economic backgrounds who are thought to have elevated risk of depression, a finding confirmed in this study, and because the $\mathrm{SH}$ question combined $\mathrm{SH}$ both with and without suicidal intent. As in other studies of adolescents self-cutting is the most common method [12]. Other than this high level of emotional symptoms, the prevalence of other risk factors such as consumption of legal or illegal substances are within the range seen in national samples of children and adolescents of similar age [28]. Thus, one clear explanation for these remarkably high levels of self-reported $\mathrm{SH}$ is socio-economic adversity; this should, therefore, be a 
Table 3 Changes in mood, suicidal thoughts, risk factors and the onset of SH

\begin{tabular}{|c|c|c|c|c|c|}
\hline Variable & $\begin{array}{l}\text { Baseline- } \\
6 \text { months }\end{array}$ & $\begin{array}{l}\text { SH at assessment } 2 / \mathrm{No} \\
\text { SH at assessment } 1\end{array}$ & $\begin{array}{l}\text { Adjusted OR } \\
(95 \% \text { CI })\end{array}$ & $\begin{array}{l}\text { Multiple adjusted } \\
\mathrm{OR}^{\mathrm{b}}(95 \% \mathrm{CI})\end{array}$ & $\begin{array}{l}\text { Overall } \\
p \text { value }\end{array}$ \\
\hline \multirow[t]{4}{*}{$\mathrm{BDI}^{\mathrm{c}}$ category } & Low-low & $87 / 1083$ & 1.0 & 1.0 & \multirow[t]{4}{*}{$<0.001$} \\
\hline & $\operatorname{High}^{\mathrm{d}}-$ low & $22 / 165$ & $1.85(1.10,3.10)$ & $1.35(0.75,2.44)$ & \\
\hline & Low-high & $42 / 150$ & $4.24(2.77,6.51)$ & $1.95(1.17,3.27)$ & \\
\hline & High-high & $69 / 183$ & $7.36(5.02,10.79)$ & $2.98(1.85,4.81)$ & \\
\hline \multirow[t]{4}{*}{ Anxiety } & Low-low & $39 / 505$ & 1.0 & 1.0 & \multirow[t]{4}{*}{0.43} \\
\hline & $\operatorname{High}^{\mathrm{e}}-$ low & $41 / 303$ & $1.81(1.13,2.90)$ & $1.37(0.80,2.33)$ & \\
\hline & Low-high & $42 / 231$ & $2.72(1.69,4.37)$ & $1.55(0.88,2.70)$ & \\
\hline & High-high & $98 / 543$ & $2.39(1.60,3.58)$ & $1.37(0.85,2.20)$ & \\
\hline \multirow[t]{4}{*}{ School connectedness } & $\operatorname{Good}^{\mathrm{f}}-\operatorname{good}$ & $67 / 601$ & 1.0 & 1.0 & \multirow[t]{4}{*}{0.39} \\
\hline & Poor-good & $32 / 235$ & $1.21(0.76,1.93)$ & $0.87(0.50,1.51)$ & \\
\hline & Good-poor & $63 / 351$ & $1.74(1.19,2.55)$ & $1.14(0.73,1.79)$ & \\
\hline & Poor-poor & $58 / 395$ & $1.40(0.96,2.06)$ & $0.76(0.47,1.21)$ & \\
\hline \multirow[t]{4}{*}{ Rational problem solving } & Good $^{\mathrm{g}}$-good & $51 / 614$ & 1.0 & 1.0 & \multirow[t]{4}{*}{0.002} \\
\hline & Poor-good & $37 / 207$ & $1.78(1.13,2.80)$ & $1.59(0.93,2.69)$ & \\
\hline & Good-poor & $50 / 249$ & $2.54(1.66,3.91)$ & $1.94(1.17,3.23)$ & \\
\hline & Poor-poor & $82 / 449$ & $2.42(1.66,3.54)$ & $2.37(1.50,3.73)$ & \\
\hline \multirow[t]{4}{*}{ Suicidal thoughts } & No-no & $88 / 1280$ & 1.0 & 1.0 & \multirow[t]{4}{*}{$<0.001$} \\
\hline & Yes-no & $19 / 76$ & $4.39(2.49,7.74)$ & $2.85(1.50,5.40)$ & \\
\hline & No-yes & $82 / 168$ & $12.02(8.24,17.54)$ & $7.77(5.11,11.81)$ & \\
\hline & Yes-yes & $30 / 54$ & $15.03(8.28,27.31)$ & $7.45(3.79,14.64)$ & \\
\hline \multirow[t]{4}{*}{ Alcohol consumption } & Never $^{\mathrm{h}}$ & $96 / 912$ & 1.0 & 1.0 & \multirow[t]{4}{*}{0.11} \\
\hline & Stop $^{\mathrm{i}}$ & $15 / 117$ & $1.27(0.70,2.29)$ & $0.91(0.46,1.81)$ & \\
\hline & Start $^{\mathrm{j}}$ & $63 / 289$ & $2.50(1.75,3.57)$ & $1.57(1.02,2.44)$ & \\
\hline & Persistent $^{\mathrm{k}}$ & $46 / 261$ & $2.00(1.34,2.98)$ & $0.90(0.53,1.53)$ & \\
\hline \multirow[t]{4}{*}{ Cannabis misuse $^{1}$} & Never & $158 / 1329$ & 1.0 & 1.0 & \multirow[t]{4}{*}{0.05} \\
\hline & Stop & $8 / 54$ & $1.16(0.51,2.65)$ & $0.88(0.33,2.35)$ & \\
\hline & Start & $34 / 132$ & $2.83(1.83,4.37)$ & $1.94(1.12,3.38)$ & \\
\hline & Persistent & $20 / 61$ & $3.92(2.17,7.06)$ & $1.98(0.92,4.25)$ & \\
\hline \multirow[t]{4}{*}{ Smoke $^{\mathrm{m}}$} & Never & $92 / 917$ & 1.0 & 1.0 & \multirow[t]{4}{*}{0.072} \\
\hline & Stop & $8 / 78$ & $1.05(0.48,2.27)$ & $0.73(0.3,1.76)$ & \\
\hline & Start & $41 / 218$ & $2.18(1.45,3.28)$ & $1.52(0.93,2.47)$ & \\
\hline & Persistent & $79 / 368$ & $2.51(1.77,3.54)$ & $1.67(1.04,2.69)$ & \\
\hline
\end{tabular}

${ }^{\mathrm{a}}$ ORs adjusted for age, gender and trial arm

${ }^{\mathrm{b}}$ ORs adjusted for age, gender, trial arm and all other variables

${ }^{c}$ Beck Depression Inventory

d $\geq 20$ in females, $\geq 14$ in males

e $\geq 7$ in females and males

$\mathrm{f} \geq 19$ in females and males

g $\geq 45$ in females and males

${ }^{\text {h }}$ Has never consumed alcohol

${ }^{\mathrm{i}} \mathrm{Had}$ consumed alcohol (at least one drink in the past 30 days) in previous assessment but has now stopped

${ }^{\mathrm{j}} \mathrm{Had}$ not consumed alcohol in the past 30 days in previous assessment but reported consuming at least one drink in subsequent assessment

${ }^{\mathrm{k}} \mathrm{Had}$ consumed alcohol in the past 30 days in previous assessment and reports consuming alcohol in present assessment

${ }^{1}$ As per d-f but the substance consumed in this case is cannabis

${ }^{m}$ As per $\mathrm{d}-\mathrm{f}$ but substance consumed is tobacco 
major concern since adversity can be even more salient in other settings.

Previous research suggests such adolescents who engage in more risky behaviours such as substance and alcohol abuse, and suffer from depressive symptoms are more likely to report $\mathrm{SH}[27,29]$. Our study is consistent with these findings: girls reporting persistent or new misuse of cannabis had over threefold increased odds of incident $\mathrm{SH}$, and high BDI-II scores were associated with an increase of more than twofold in both boys and girls. These associations were, however, attenuated after adjusting for other measured psychological risk factors (anxiety, school connectedness and problem-solving skills).

Nonetheless, the association with the use of addictive substances may be of importance at a time when use of these substances, particularly among girls, is increasingly reported throughout the world [30]. When considering those changes in behaviour associated with incident $\mathrm{SH}$, initial strong associations with the consumption of substances were explained to some extent by the presence of depressive symptoms and suicidal thoughts. There was evidence of a strong association between suicidal thoughts and the onset of $\mathrm{SH}$. We also found that gender differences around reporting $\mathrm{SH}$ with suspected suicidal intent (classified as ingesting pills or poison) were significantly more marked than those seen in several previous studies with incident self-harming girls much more likely to report SH with suicidal intent than incident self-harming boys [12, 15]. Therefore, most of our findings point toward an increased level of emotional symptoms as the most likely explanation for the high levels of $\mathrm{SH}$ seen in this population.

A new finding in this study is the assessment of problemsolving skills, which remained inversely associated with future risk of incident $\mathrm{SH}$ in both boys and girls even after adjusting for suicidal thoughts, depression and other risk factors. This finding was consistent for individuals with recent or persistent difficulties in solving problems, even though one would expect that adolescents with persistent difficulties to solve problems would be more likely to resort to SH. This is in keeping with theories that suggest problem-solving and coping skills act as protective factors against the development of suicidality, and that such skills may be on the pathway between adverse life stress and depression, feeling hopeless and thoughts of suicide [31]. A review by Nock suggests that people with a recent history of SH show vulnerabilities of poor ability to tolerate experienced distress, with poor verbal, communication and social problem-solving skills [32]. Other research including measures of problem-solving ability found self-harmers were more likely to have deficits in social problem-solving abilities [33]. This finding is also supportive of theories suggesting that $\mathrm{SH}$ tends to peak in adolescence because some individuals at this age may not have yet developed skills to cope with the huge volume of developmental changes as well as stress present in adolescence. Besides this it is an important finding from a practical point of view because it suggests that programmes aiming to improve these skills might help in decreasing the risk of SH.

Strengths and limitations

Strengths of this study include the prospective design with a high rate of questionnaire completion (81\%). The sample available to investigate incident $\mathrm{SH}$ is large, and includes detailed measures of psychopathology and substance abuse within a unique, socio-economically deprived, adolescent population from a middle income country. In addition to these, this study included exposures such as ability to solve problems, never tested in a prospective, longitudinal study before. There is also confidence in the high reporting of $\mathrm{SH}$, with over $93 \%$ of individuals also reporting a method.

Although there have been several longitudinal studies that have explored risk factors of $\mathrm{SH}$, most are from Western countries [11, 34, 35]. This study is an important addition to the literature with a large longitudinal sample of adolescents from a non-western setting. Moreover, this is one of few studies to include a measure of an individual's problem-solving ability.

Limitations of the study are that data were collected as part of a randomised trial for which $\mathrm{SH}$ was not the main focus, thus the $\mathrm{SH}$ variables are not as detailed as we might wish. For example, the question relating to $\mathrm{SH}$ addresses both an intent to take their own life and $\mathrm{SH}$ behaviours in a single question; there is, therefore, no clear distinction between those students with more serious intent of suicide and those chronic self-harmers who may be less likely to seek help. This question used to assess SH could also have been interpreted in more than one way. For example, someone may have thought about taking his own life but changed his/her mind without engaging in any specific $\mathrm{SH}$ act. We were reassured, however, that within our analysis of those answering yes to this question at 6-month follow-up, and thus defined as incident self-harmers, $96 \%$ reported the method of SH. We also attempted to address this using this subsequent $\mathrm{SH}$ method question as a proxy for $\mathrm{SH}$ with or without suicidal intent. Our questionnaire enquired upon behaviours over the last 30 days so we do not cover the entire period of 6 months since baseline $* * * *$. In that respect our findings can be considered as conservative estimates but we opted for this to improve the accuracy of reporting, as it is known that retrospective reporting for longer periods decrease the accuracy of the data.

It is important to note that the question about thoughts of ending their life did not relate to the possible presence of harming oneself with no intent to end their life; we therefore refer only to suicidal thoughts and not SH thoughts. As with all self-report questionnaires answers may be subject 
to reporting or recall bias. As the data were being collected as part of a trial this was adjusted for in all analyses, with trial arm included in all statistical models.

Variables used to classify presence of 'risky behaviour', including smoking, alcohol and cannabis misuse, were subject to dichotomisation; however we were primarily interested in the presence or absence of such behaviours and not the extent to which individuals engaged in such behaviour. With regards to missing data, it is recognised that those who frequently $\mathrm{SH}$ are likely to have low school attendance, as well as being less likely to respond to questions regarding $\mathrm{SH}$. This would infer that estimates of $\mathrm{SH}$ prevalence amongst adolescents obtained from questionnaires administered at schools are likely to be lower than the general population prevalence of $\mathrm{SH}$ and ideation [5]. Those missing may also be more likely to have some form of mental, impulse control or substance use disorder putting them at higher risk of SH and completed suicide [36]. Taking into account the question used to assess $\mathrm{SH}$ and the implications of missing data, the prevalence observed in this study may equally underestimate the true population prevalence.

Despite these limitations the study documents $\mathrm{SH}$ within an economically deprived community of young adolescents, something which is rarely done, as well as focussing on the incidence of $\mathrm{SH}$ with reasonably small attrition rates, its association with other harmful behaviours in adolescents, change over time of these risk factors as well as gender differences in type of $\mathrm{SH}$ reported.

\section{Implications}

These findings highlight the magnitude of a problem rarely reported from non-western settings. SH is potentially a major event in the life of those affected and those surrounding them and given the magnitude of the problem hereby noted it should be a major public health concern. Although some of the risk factors identified have been previously reported from studies in developed countries, the clear association of $\mathrm{SH}$ and poor problem-solving skills is a novel finding. This finding may suggest that interventions aiming to both improve these skills as well as aiming to prevent their deterioration could have an impact on reducing $\mathrm{SH}$. It is however important to bear in mind that this is a population most likely affected by a large burden of social problems and it remains to be seen whether or not better problem-solving skills can be taught and whether or not this might result in reduced $\mathrm{SH}$ within this context. It is also important to think of these risk factors within a longitudinal, life-course perspective. Many of these associations follow a bi-directional nature over time [35], with prevalent $\mathrm{SH}$ being further predictive of psychological problems, particularly amongst girls, as well as of adult depression and substance use [34] and the presence of drug, alcohol and psychological problems in those who repeatedly SH [37] Nonetheless most previous research shows that the antecedent of $\mathrm{SH}$ often accompanied by a myrad of other behavioural and emotional correlates is a strong predictor of later problems, including suicide [11, 34]. Given these consistent associations along with evidence found in previous research of the pathway from $\mathrm{SH}$ to suicide, it seems important that $\mathrm{SH}$ and mental disorders in adolescence are recognised and treated as a way of preventing suicide and more importantly to improve the future functioning of those affected.

Acknowledgments This research was funded by the Wellcome Trust. The views and opinions expressed therein are those of the authors and do not necessarily reflect those of the funding body. DG is an NIHR Senior Investigator. We wish to thank all the young people who took part in this research, the staff at participating schools, and our team of research assistants for their support with this research.

\section{Conflict of interest None.}

Open Access This article is distributed under the terms of the Creative Commons Attribution License which permits any use, distribution, and reproduction in any medium, provided the original author(s) and the source are credited.

\section{References}

1. Viner RM, Coffey C, Mathers C, Bloem P, Costello A, Santelli J, Patton GC (2011) 50-year mortality trends in children and young people: a study of 50 low-income, middle-income, and highincome countries. Lancet 377(9772):1162-1174. doi:10.1016/ S0140-6736(11)60106-2

2. Zahl DL, Hawton K (2004) Repetition of deliberate self-harm and subsequent suicide risk: long-term follow-up study of 11,583 patients. Br J Psychiatry J Ment sci 185:70-75

3. Hawton K, James A (2005) Suicide and deliberate self harm in young people. BMJ 330(7496):891-894. doi:10.1136/bmj.330. 7496.891

4. Patton GC, Hemphill SA, Beyers JM, Bond L, Toumbourou JW, McMorris BJ, Catalano RF (2007) Pubertal stage and deliberate self-harm in adolescents. J Am Acad Child Adolesc Psychiatry 46(4):508-514. doi:10.1097/chi.0b013e31803065c7

5. Madge N, Hewitt A, Hawton K, de Wilde EJ, Corcoran P, Fekete S, van Heeringen K, De Leo D, Ystgaard M (2008) Deliberate self-harm within an international community sample of young people: comparative findings from the Child \& Adolescent Selfharm in Europe (CASE) Study. J Child Psychol Psychiatry 49(6):667-677. doi:10.1111/j.1469-7610.2008.01879.x

6. Morey C, Corcoran P, Arensman E, Perry IJ (2008) The prevalence of self-reported deliberate self harm in Irish adolescents. BMC Public Health 8:79. doi:10.1186/1471-2458-8-79

7. Landstedt E, Gillander Gadin K (2011) Deliberate self-harm and associated factors in 17-year-old Swedish students. Scand J Public Health 39(1):17-25. doi:10.1177/1403494810382941

8. Hawton K, Rodham K, Evans E, Weatherall R (2002) Deliberate self harm in adolescents: self report survey in schools in England. BMJ 325(7374):1207-1211

9. Laukkanen E, Rissanen ML, Honkalampi K, Kylma J, Tolmunen T, Hintikka J (2009) The prevalence of self-cutting and other self- 
harm among 13- to 18-year-old Finnish adolescents. Soc Psychiatry Psychiatr Epidemiol 44(1):23-28. doi:10.1007/s00127008-0398-x

10. O'Connor RC, Rasmussen S, Miles J, Hawton K (2009) Selfharm in adolescents: self-report survey in schools in Scotland. $\mathrm{Br}$ J psychiatry J Ment sci 194(1):68-72. doi:10.1192/bjp.bp.107. 047704

11. Fergusson DM, Woodward LJ, Horwood LJ (2000) Risk factors and life processes associated with the onset of suicidal behaviour during adolescence and early adulthood. Psychol Med 30(1):23-39

12. Moran P, Coffey C, Romaniuk H, Olsson C, Borschmann R, Carlin JB, Patton GC (2012) The natural history of self-harm from adolescence to young adulthood: a population-based cohort study. Lancet 379(9812):236-243. doi:10.1016/S01406736(11)61141-0

13. Madge N, Hawton K, McMahon EM, Corcoran P, De Leo D, de Wilde EJ, Fekete S, van Heeringen K, Ystgaard M, Arensman E (2011) Psychological characteristics, stressful life events and deliberate self-harm: findings from the Child \& Adolescent Selfharm in Europe (CASE) Study. Eur Child Adolesc Psychiatry 20(10):499-508. doi:10.1007/s00787-011-0210-4

14. Kidger J, Heron J, Lewis G, Evans J, Gunnell D (2012) Adolescent self-harm and suicidal thoughts in the ALSPAC cohort: a self-report survey in England. BMC Psychiatry 12(1):69. doi:10. 1186/1471-244X-12-69

15. Vijayakumar L, Nagaraj K, Pirkis J, Whiteford H (2005) Suicide in developing countries (1): frequency, distribution, and association with socioeconomic indicators. Crisis 26(3):104-111

16. Borges G, Nock MK, Medina-Mora ME, Benjet C, Lara C, Chiu WT, Kessler RC (2007) The epidemiology of suicide-related outcomes in Mexico. Suicide Life Threat Behav 37(6):627-640. doi:10.1521/suli.2007.37.6.627

17. Vijayakumar L, John S, Pirkis J, Whiteford H (2005) Suicide in developing countries (2): risk factors. Crisis 26(3):112-119

18. Eskin M, Ertekin K, Dereboy C, Demirkiran F (2007) Risk factors for and protective factors against adolescent suicidal behavior in Turkey. Crisis 28(3):131-139

19. Pollock LR, Williams JM (2004) Problem-solving in suicide attempters. Psychol Med 34(1):163-167

20. Araya R, Montgomery AA, Fritsch R, Gunnell D, Stallard P, Noble S, Martinez V, Barroilhet S, Vohringer P, Guajardo V, Cova F, Gaete J, Gomez A, Rojas G (2011) School-based intervention to improve the mental health of low-income, secondary school students in Santiago, Chile (YPSA): study protocol for a randomized controlled trial. Trials 12:49

21. Beck AT, Steer RA, Brown GK (1996) BDI-II: Beck Depression Inventory manual, vol Second. The Psychological Corporation, San Antonio

22. Melipillán RCF, Rincón R, Valdivia M (2008) Propiedades Psicométricas del Inventario de Depresión de Beck-II en Adolescentes Chilenos. Terapia psicológica 26(1):59-69. doi:10. 4067/S0718-48082008000100005
23. Chorpita BF, Yim L, Moffitt C, Umemoto LA, Francis SE (2000) Assessment of symptoms of DSM-IV anxiety and depression in children: a revised child anxiety and depression scale. Behav Res Ther 38(8):835-855

24. Goodenow C (1991) The psychological sense of school membership among adolescents: scale development and educational correlates. Psychol Sch 30:79-90

25. D'Zurilla TJNA, Maydeu-Olivares A (2002) Social problemsolving inventory-revised: technical manual. Multi-Health Systems, North Tonawanda

26. Nock MK, Borges G, Bromet EJ, Cha CB, Kessler RC, Lee S (2008) Suicide and suicidal behavior. Epidemiol Rev 30:133-154. doi:10.1093/epirev/mxn002

27. Skegg K (2005) Self-harm. Lancet 366(9495):1471-1483. doi:10. 1016/S0140-6736(05)67600-3

28. Publica MdIy S (2012) Noveno estudio nacional de drogas en poblacion escolar. Principales resultados. Observatorio Chileno de Drogas, SENDA

29. Tormoen AJ, Rossow I, Larsson B, Mehlum L (2012) Nonsuicidal self-harm and suicide attempts in adolescents: differences in kind or in degree? Soc Psychiatry Psychiatr Epidemiol. doi:10. 1007/s00127-012-0646-y

30. [PATS] PATS (2009) PATS teens 2008 report

31. Yang B, Clum GA (1994) Life stress, social support, and problem-solving skills predictive of depressive symptoms, hopelessness, and suicide ideation in an Asian student population: a test of a model. Suicide Life Threat Behav 24(2):127-139

32. Nock MK (2010) Self-injury. Annu Rev Clin Psychol 6:339-363. doi:10.1146/annurev.clinpsy.121208.131258

33. Nock MK, Mendes WB (2008) Physiological arousal, distress tolerance, and social problem-solving deficits among adolescent self-injurers. J Consult Clin Psychol 76(1):28-38. doi:10.1037/ 0022-006X.76.1.28

34. Fergusson DM, Horwood LJ, Ridder EM, Beautrais AL (2005) Suicidal behaviour in adolescence and subsequent mental health outcomes in young adulthood. Psychol Med 35(7):983-993

35. Lundh LG, Wangby-Lundh M, Bjarehed J (2011) Deliberate selfharm and psychological problems in young adolescents: evidence of a bidirectional relationship in girls. Scand $\mathrm{J}$ Psychol 52(5):476-483. doi:10.1111/j.1467-9450.2011.00894.x

36. Benjet C, Borges G, Medina-Mora ME, Zambrano J, AguilarGaxiola S (2009) Youth mental health in a populous city of the developing world: results from the Mexican adolescent mental health survey. J Child Psychol Psychiatry 50(4):386-395. doi:10. 1111/j.1469-7610.2008.01962.x

37. Haw C, Bergen H, Casey D, Hawton K (2007) Repetition of deliberate self-harm: a study of the characteristics and subsequent deaths in patients presenting to a general hospital according to extent of repetition. Suicide Life Threat Behav 37(4):379-396. doi:10.1521/suli.2007.37.4.379 